\title{
PENENTUAN SOLUSI PERSAMAAN PELL
}

\author{
AULIA NABILA, YANITA, ADMI NAZRA \\ Program Studi S1 Matematika, \\ Fakultas Matematika dan Ilmu Pengetahuan Alam, Universitas Andalas, \\ Kampus UNAND Limau Manis Padang, Indonesia, \\ email : anblaa19@gmail.com
}

\begin{abstract}
Abstrak. Persamaan Diophantine merupakan persamaan polynomial yang solusinya berada di himpunan bilangan bulat. Persamaan Diophantine terbagi dua, yaitu persamaan Diophantine linier dan persamaan Diophantine tidak linier. Persamaan Diophantine tidak linier yang berbentuk $x^{2}-D y^{2}=1$ dimana $D$ bukan merupakan bilangan kuadrat, dengan $(x, y)$ adalah solusi, disebut persamaan Pell. Salah satu cara untuk menentukan solusi persamaan Pell, $\left(x_{k}, y_{k}\right)$, jika $\left(x_{1}, y_{1}\right)$ diketahui adalah :
\end{abstract}

$$
\left(x_{k}+y_{k} \sqrt{D}\right)=\left(x_{1}+y_{1} \sqrt{D}\right)^{k}, \text { untuk } k=1,2,3, \cdots .
$$

Kata Kunci: Persamaan Diophantine, solusi persamaan Pell

$\begin{array}{lll}\text { Diterima } & : & 26 \text { Juli } 2018 \\ \text { Direvisi } & : & 17 \text { September } 2018 \\ \text { Dipublikasikan } & : & 21 \text { Desember 2018 }\end{array}$

\section{Pendahuluan}

Persamaan Pell merupakan salah satu bentuk persamaan Diophantine, karena persamaan Pell memiliki tak hingga banyaknya solusi $(x, y)$ di himpunan bilangan bulat. Bentuk umum dari persamaan Pell adalah

$$
x^{2}-D y^{2}=1
$$

dimana $x, y, D \in \mathbb{Z}$, dan $D$ bukan merupakan bilangan kuadrat (nonsquare number).

Oleh karena persamaan Pell memiliki tak hingga banyaknya solusi $(x, y)$ di himpunan bilangan bulat, maka makalah ini akan mengkaji cara menentukan solusi persamaan Pell jika solusi $\left(x_{1}, y_{1}\right)$ diketahui.

\section{Persamaan Diophantine}

Persamaan Diophantine adalah polinomial dengan satu atau lebih variabel dan koefsien di himpunan bilangan bulat. Persamaan Diophantine terdiri dari persamaan Diophantine linier dan persamaan Diophantine tidak linier. Bentuk paling sederhana dari persamaan Diophantine linier dengan dua variabel $x$ dan $y$ adalah $a x+b y=c$ dimana $a, b, c \in \mathbb{Z}$. Sedangkan salah satu bentuk dari persamaan Diophantine tidak linier dengan dua variabel $x$ dan $y$ adalah $a x^{n}+b y^{n}=c$. 


\section{Bilangan Kuadrat Segitiga}

Bilangan kuadrat segitiga adalah bilangan yang termasuk bilangan kuadrat dan bilangan segitiga.

Teorema 3.1. [2] Bilangan kuadrat segitiga bersesuaian dengan persamaan $x^{2}-$ $2 y^{2}=1$, dimana $x, y \in \mathbb{Z}^{+}$.

Bukti. Diketahui bentuk umum dari bilangan segitiga adalah $T_{m}=\frac{m(m+1)}{2}, m \in$ $\mathbb{Z}$, dan bentuk umum dari bilangan kuadrat adalah $S_{n}=n^{2}, n \in \mathbb{Z}$.

Akan dibuktikan bilangan kuadrat segitiga bersesuaian dengan persamaan $x^{2}-$ $2 y^{2}=1$, dimana $x, y \in \mathbb{Z}^{+}$.

Perhatikan bahwa:

$$
\begin{aligned}
T_{m} & =S_{n} \\
\frac{m(m+1)}{2} & =n^{2} \\
m^{2}+m & =2 n^{2} \\
\left(m+\frac{1}{2}\right)^{2}-\frac{1}{4} & =2 n^{2} \\
(2 m+1)^{2}-1 & =2(2 n)^{2} \\
(2 m+1)^{2}-2(2 n)^{2} & =1 .
\end{aligned}
$$

Berdasarkan persamaan di atas, maka bilangan kuadrat segitiga bersesuaian dengan persamaan $x^{2}-2 y^{2}=1$, dengan $x=2 m+1$ dan $y=2 n$. Karena $m, n \in \mathbb{Z}$, maka $x, y \in \mathbb{Z}$.

Teorema 3.2. [2] Setiap solusi $\left(x_{k}, y_{k}\right)$, dimana $x_{k}, y_{k} \in \mathbb{Z}^{+}$, untuk persamaan $x^{2}-2 y^{2}=1$ dapat diperoleh dari $x_{k}+y_{k} \sqrt{2}=(3+2 \sqrt{2})^{k}$ untuk $k=1,2,3$, cdots .

Bukti. Misalkan $(u, v)$ solusi dari $x^{2}-2 y^{2}=1$, dimana $u, v \in \mathbb{Z}^{+}$.

Akan dibuktikan $u+v \sqrt{2}=(3+2 \sqrt{2})^{k}$.

Misalkan $u<3$. Perhatikan bahwa dengan menggunakan trial and error, persamaan $x^{2}-2 y^{2}=1$ memiliki solusi yaitu $\left(x_{1}, y_{1}\right)=(3,2)$. Akibatnya jika $u<3$ maka solusi $(u, v)$ tidak memenuhi persamaan $x^{2}-2 y^{2}=1$.

Misalkan $u=3$. Karena solusi $\left(x_{1}, y_{1}\right)=(3,2)$ untuk persamaan $x^{2}-2 y^{2}=1$ adalah $(3,2)$, maka terbukti $(u, v)$ memenuhi persamaan $x^{2}-2 y^{2}=1$.

Misalkan $u>3$, akan ditunjukkan ada solusi lain $(s, t)$ pada bilangan bulat positif sedemikian sehingga

$$
u+v \sqrt{2}=(3+2 \sqrt{2})(s+t \sqrt{2}), s<u .
$$

Perhatikan bahwa :

$$
\begin{aligned}
u+v \sqrt{2} & =(3+2 \sqrt{2})(s+t \sqrt{2}) \\
& =(3 s+4 t)+(2 s+3 t) \sqrt{2} .
\end{aligned}
$$

Sehingga,

$$
u=3 s+4 t, v=2 s+3 t .
$$


Akibatnya,

$$
s=3 u-4 v, t=-2 u+3 v .
$$

Untuk menguji nilai $(s, t)$, perhatikan bahwa :

$$
\begin{aligned}
s^{2}-2 t^{2} & =(3 u-4 v)^{2}-2(-2 u+3 v)^{2} \\
& =\left(9 u^{2}-24 u v+16 v^{2}\right)-2\left(4 u^{2}-12 u v+9 v^{2}\right) \\
& =u^{2}-2 v^{2} \\
& =1 .
\end{aligned}
$$

Selanjutnya akan dibuktikan apakah $s$ bernilai positif.

Perhatikan bahwa :

$$
u^{2}=1+2 v^{2}>2 v^{2},
$$

maka $u>\sqrt{2} v$. Sehingga

$$
s=3 u-4 v>3 \sqrt{2} v-4 v=(3 \sqrt{2}-4) v>0 .
$$

Terbukti $s$ bernilai positif.

Selanjutnya akan dibuktikan apakah $t$ bernilai positif.

Perhatikan bahwa:

$$
\begin{aligned}
u & >3 \\
u^{2} & >9 \\
9 u^{2} & >9+8 u^{2} \\
9 u^{2}-9 & >8 u^{2} \\
u^{2}-1 & >\frac{8}{9} u^{2} \\
2 v^{2} & >\frac{8}{9} u^{2} \\
v & >\frac{2}{3} u .
\end{aligned}
$$

Perhatikan bahwa $t=-2 u+3 v$. Dengan menggunakan ketidaksamaan di atas, maka

$$
t=-2 u+3 v>-2 u+3 \cdot \frac{2}{3} u=0 .
$$

Sehingga terbukti $t$ bernilai positif.

Karena $s$ dan $t$ bernilai positif dan $u=3 s+4 t$ maka $s<u$. Akibatnya jika $u>3$ ada solusi lain $(s, t)$ pada bilangan bulat positif sedemikian

$$
u+v \sqrt{2}=(3+2 \sqrt{2})(s+t \sqrt{2}), s<u .
$$

\section{Persamaan Pell}

Definisi 4.1. [2] Persamaan Pell adalah persamaan Diophantine dalam bentuk $x^{2}-$ $D y^{2}=1, x, y, D \in \mathbb{Z}^{+}$, dan $D$ bukan merupakan bilangan kuadrat (nonsquare number). 
Teorema 4.2. [3] Jika $\left(x_{1}, y_{1}\right)$ dan $\left(x_{2}, y_{2}\right)$ merupakan solusi dari persamaan Pell, $x^{2}-D y^{2}=k$, sedemikian hingga $x_{1} \equiv x_{2}(\bmod k)$ dan $y_{1} \equiv y_{2}(\bmod k)$, maka persamaan Pell $x^{2}-D y^{2}=1$ memiliki solusi dalam bentuk bilangan bulat positif.

Bukti. Misalkan $\left(x_{1}, y_{1}\right)$ dan $\left(x_{2}, y_{2}\right)$ solusi dari persamaan Pell, maka $x_{1}^{2}-D y_{1}^{2}=k$ dan $x_{2}^{2}-D y_{2}^{2}=k$.

Perhatikan bahwa:

$$
\begin{aligned}
k^{2} & =\left(x_{1}^{2}-D y_{1}^{2}\right)\left(x_{2}^{2}-D y_{2}^{2}\right) \\
& =x_{1}^{2} x_{2}^{2}-D x_{1}^{2} y_{2}^{2}-D x_{2}^{2} y_{1}^{2}+D^{2} y_{1}^{2} y_{2}^{2} \\
& =\left(x_{1}^{2} x_{2}^{2}-2 D x_{1} x_{2} y_{1} y_{2}+D^{2} y_{1}^{2} y_{2}^{2}\right)-D\left(x_{1}^{2} y_{2}^{2}-2 x_{1} x_{2} y_{1} y_{2}+x_{2}^{2} y_{1}^{2}\right) \\
& =\left(x_{1} x_{2}-D y_{1} y_{2}\right)^{2}-D\left(x_{1} y_{2}-x_{2} y_{1}\right)^{2} \\
1 & =\left(\frac{x_{1} x_{2}-D y_{1} y_{2}}{k}\right)^{2}-D\left(\frac{x_{1} y_{2}-x_{2} y_{1}}{k}\right)^{2} .
\end{aligned}
$$

Karena $x_{1} \equiv x_{2}(\bmod k)$ dan $y_{1} \equiv y_{2}(\bmod k)$, maka

$$
x_{1} x_{2}-D y_{1} y_{2} \equiv x_{1} x_{1}-D y_{1} y_{1}=x_{1}^{2}-D y_{1}^{2} .
$$

Karena $x_{1}^{2}-D y_{1}^{2}=k$ dan $k \equiv 0(\bmod k)$, maka $x_{1}^{2}-D y_{1}^{2} \equiv 0(\bmod k)$, sehingga $x_{1} x_{2}-D y_{1} y_{2} \equiv x_{1}^{2}-D y_{1}^{2} \equiv 0(\bmod k)$. Akibatnya

$$
\left(\frac{x_{1} x_{2}-D y_{1} y_{2}}{k}, \frac{x_{1} y_{2}-x_{2} y_{1}}{k}\right)
$$

adalah solusi bilangan bulat untuk persamaan Pell $x^{2}-D y^{2}=1$.

Teorema 4.3. [1] Jika $\left(x_{1}, y_{1}\right)$ adalah solusi minimal dari persamaan Pell, maka setiap solusi $\left(x_{k}, y_{k}\right)$ dapat dicari dengan

$$
x_{k}+y_{k} \sqrt{D}=\left(x_{1}+y_{1} \sqrt{D}\right)^{k}, k=1,2,3, \cdots
$$

dimana $x_{1}, y_{1}, x_{k}, y_{k} \in \mathbb{Z}^{+}$.

Bukti. Misalkan $\left(x_{1}, y_{1}\right)$ adalah solusi minimal dari persamaan Pell, dimana $x_{1}, y_{1} \in \mathbb{Z}^{+}$.

Akan dibuktikan setiap solusi $\left(x_{k}, y_{k}\right)$ dapat dicari dengan

$$
x_{k}+y_{k} \sqrt{D}=\left(x_{1}+y_{1} \sqrt{D}\right)^{k}, k=1,2,3, \cdots .
$$

Perhatikan bahwa $x_{k}+y_{k} \sqrt{D}>1$ dan $\left(x_{1}+y_{1} \sqrt{D}\right)^{k}$ untuk $k=1,2,3$, cdots dapat bernilai 1 sampai $\infty$, sehingga $x_{k}+y_{k} \sqrt{D}$ berada pada selang

$$
\left(x_{1}+y_{1} \sqrt{D}\right)^{k} \leq x_{k}+y_{k} \sqrt{D}<\left(x_{1}+y_{1} \sqrt{D}\right)^{k+1}
$$

untuk $k \geq 0$. Dengan membagi persamaan di atas dengan $\left(x_{1}+y_{1} \sqrt{D}\right)^{k}$, maka

$$
1 \leq\left(x_{k}+y_{k} \sqrt{D}\right)\left(x_{1}+y_{1} \sqrt{D}\right)^{-k}<x_{1}+y_{1} \sqrt{D} .
$$

Misalkan $\left(x_{k}+y_{k} \sqrt{D}\right)\left(x_{1}-y_{1} \sqrt{D}\right)^{k}=a+b \sqrt{D}$. Maka,

$$
1 \leq a+b \sqrt{D}<x_{1}+y_{1} \sqrt{D} .
$$


Jika $1<a+b \sqrt{D}$ maka $a$ dan $b$ bernilai positif, sehingga $b<y_{1}$. Hal ini kontradiksi terhadap pernyataan bahwa $y_{1}$ bernilai minimal. Maka haruslah $1=a+b \sqrt{D}$ yang berarti

$$
x_{k}+y_{k} \sqrt{D}=\left(x_{1}+y_{1} \sqrt{D}\right)^{k}, \text { untuk } k=1,2,3, \cdots .
$$

Sehingga terbukti bahwa setiap solusi $\left(x_{k}, y_{k}\right)$ dapat dicari dengan

$$
x_{k}+y_{k} \sqrt{D}=\left(x_{1}+y_{1} \sqrt{D}\right)^{k}, \text { untuk } k=1,2,3, \cdots .
$$

\section{Ucapan Terima kasih}

Terima kasih kepada ibu Nova Noliza Bakar, M.Si, ibu Dr. Haripamyu, bapak Budi Rudianto, M.Si, selaku dosen penguji, yang telah memberikan kritik dan saran dalam penulisan makalah ini.

\section{Daftar Pustaka}

[1] Conrad, K. Pell's Equation I. University of Connecticut, United State of America.

[2] Silverman, J.H. 2011. A Friendly Introduction to Number Theory. Pearson Inc, New Jersey $31: 237-266$.

[3] Wright, M. 2006. Solving Pell Equation. Department of Mathematical Sciences, Messiah College, United State of America 1:3-14. 